\title{
Assessment of the effects of monosodium glutamate on some biochemical and hematological parameters in adult wistar rats
}

\author{
Oyetunji Timothy Kolawole \\ Department of Pharmacology and Therapeutics, College of Health Sciences, Ladoke Akintola University of Technology, Ogbomoso, \\ Nigeria
}

Email address:

tymkol@yahoo.co.uk

\section{To cite this article:}

Oyetunji Timothy Kolawole. Assessment of the Effects of Monosodium Glutamate on Some Biochemical and Hematological Parameters in Adult Wistar Rats. American Journal of BioScience. Vol. 1, No. 1, 2013, pp. 11-15. doi: 10.11648/j.ajbio.20130101.13

\begin{abstract}
Monosodium glutamate (MSG) is a compound popularly used to enhance food taste and flavor. Several reports of toxicity studies on MSG are contradictory. Therefore, there is growing concern regarding the safety of MSG as food additive. In the present study, the effect of orally administered MSG on food consumption, body weight and some biochemical and hematological parameters were investigated in adult rats. Following a 28 -day treatment with $5-15 \mathrm{mg} / \mathrm{kg}$ body weight MSG, there were no significant changes in packed cell volume (PCV), hemoglobin concentration (HB), red blood cell (RBC) and white blood cell (WBC) counts. No significant change was also observed in all the biochemical parameters studied, including indices of hepatic and renal functions. The results of this study suggest that MSG at the doses administered is not hazardous to health.
\end{abstract}

Keywords: Monosodium Glutamate, Toxicity, Body Weight, Food Additive, Enzymes

\section{Introduction}

In order to enjoy food, taste and flavor are necessary. A tasteless food even when composed of required nutritional elements is usually rejected. Therefore food flavoring is important especially in elderly persons who have irreversible chemosensory deficit. In such individuals, it is necessary to improve appetite to ensure adequate dietary intake. Flavor enhancers are also useful in situations where salt intake needs to be reduced such as in hypertension [1]. Glutamate possesses umami taste which enhances food palatability and encourages flavor acceptance [2]. It is one of the non-essential amino acids that are synthesized endogenously. It is a component of many proteins and peptides. When bound to proteins, glutamate is tasteless. The sweet umami taste and flavor becomes perceptible only when free glutamate dissociates from proteins during the processes of fermentation, ripening and cooking [3]. Tomatoes, cheese and mushrooms contain large quantity of glutamate and are thus used to enrich the taste and flavor of foods [4]. However, the use of excess amount of glutamate actually makes food more distasteful rather than impart good taste [4].
Monosodium glutamate (MSG) is the sodium salt of glutamate.

MSG is produced commercially by fermentation of molasses; it is used in home cooking, restaurants and for industrial food production around the world [5]. In recent years, there has been much concern about possible adverse effects of MSG. It is believed to be the cause of Chinese restaurant syndrome which is characterized by headache, flushing, numbness, muscle tightness, generalized weakness and broncho-constriction in asthmatics [6]. Consumption of glutamate has been linked to obesity and metabolic syndrome independent of physical activity and calorie intake [7]. Some researchers have also reported neurotoxic effects of glutamate [8].

However, the literature is also full of contrary reports. In fact, the general consensus among scientists was that glutamate is safe even in children, pregnant women and lactating mothers [9]. It was shown that glutamate has very low acute and chronic toxicity profile under normal circumstance. The oral median lethal dose $\left(\mathrm{LD}_{50}\right)$ in rats and mice were reported to be 15,000 and $18,000 \mathrm{mg} / \mathrm{kg}$ respectively [10]. Several studies have also shown that glutamate did not increase food intake or induce weight 
gain $[11,12]$.

Considering the discrepancies in the literature and the growing safety concern for the use of monosodium glutamate, there is need for further studies on this important food additive. In this study, the effects of monosodium glutamate on food consumption, body weight and some hematological and biochemical parameters were studied in adult rats.

\section{Materials and Methods}

\subsection{Chemicals}

Monosodium glutamate (MSG) was purchased from a reputable market in Osogbo, Nigeria. All other chemicals used were of analytical grade.

\subsection{Experimental Animals}

Healthy Wistar rats weighing between 180 and $200 \mathrm{~g}$ were obtained from the Laboratory Animal House, College of Health Sciences, Ladoke Akintola University of Technology (LAUTECH), Ogbomoso, Nigeria. They were kept in a well-ventilated and hygienic laboratory environment. The rats were allowed free access to standard rat feed pellets and clean water ad libitum. All experimental procedures were conducted in accordance with National Institute of Health Guide for the Care and Use of Laboratory Animals [13] as well as Ethical Guidelines for the Use of Laboratory Animals in LAUTECH, Ogbomoso, Nigeria.

\subsection{Experimental Procedure}

Rats were randomly divided into 4 groups of 6 rats each. Group 1 served as the control and received normal saline (3 $\mathrm{ml} / \mathrm{kg}$ ). Groups 2, 3 and 4 were treated with 5, 10 and 15 $\mathrm{mg} / \mathrm{kg}$ of MSG respectively for 28 days. All drugs were administered orally. After the 28-day treatment, rats were anesthetized with diethyl ether and blood was collected by cervical decapitation into clean lithium heparin bottles. Blood sample was centrifuged for $5 \mathrm{~min}$ and the plasma obtained was subsequently used for biochemical assays. Whole blood was used for hematological study.

\subsection{Estimation of Food Consumption and Body Weight}

Food consumption was evaluated daily as known amount of food was given to each animal in a cage. After $24 \mathrm{~h}$, the remaining food was taken from the cage and weighed. To determine the quantity of feed consumed, the left-over was deducted from the total amount initially provided. Food intake was calculated as g/day. Body weight of the rats was measured every week for the four weeks of the experiment.

\subsection{Hematological and Biochemical Studies}

Red blood cell and white blood cell counts were determined using improved Nuebauer hemocytometer [14]. Albumin was estimated colorimetrically using Sigma Diagnostic albumin reagents (Sigma Diagnostic, UK). Total protein was measured by Randox kit formulated for Biuret reaction. Globulin was calculated as the difference between total protein and albumin. Hemoglobin concentration was determined by cyanomethemoglobin method [15]. Packed cell volume (PCV) was determined using Hawskley microhematocrit centrifuge at $12,000 \mathrm{~g}$ for $5 \mathrm{~min}$ [14]. Bilirubin was measured colorimetrically using assay kits (BioAssay Systems, USA). Alanine aminotransferase (ALT), aspartate aminotransferase (AST), alkaline phosphatase (ALP) as well as creatinine and urea levels were estimated by the method described by Toro and Ackermann [16].

\subsection{Statistical Analysis}

Data obtained from the experiments were expressed as mean \pm standard error of mean (SEM). For statistical analysis, data were subjected to one-way analysis of variance (ANOVA) followed by Student's t- test. A level of $P<0.05$ was acceptable as significant unless otherwise stated. GraphPad Prism version 5.0 for windows was used for these statistical analyses (GraphPad software, San Diego California USA).

\section{Results and Discussion}

To enjoy good quality of life, consumption of healthy and nutritious food is important. Eating food should also be pleasurable. It is therefore a common practice all over the world to amplify the taste and flavor of foods by means of food additives, especially monosodium glutamate (MSG). Potential consumers are usually attracted to industrially prepared foods because of the characteristic umami taste and the typical flavors imparted by MSG [17]. However, when enhancing palatability, it is also of paramount importance to ensure that food additives will not cause harm to the consumers.

The literature is full of contradictory reports on the level of toxicity of MSG in animal and human experiments. Previous studies suggest that MSG increases, decreases or has no effect on the body weight of rodents. Kondoh and Torii [11] reported that MSG-treated rats had a significantly smaller weight gain, reduced abdominal fat mass, and lower plasma leptin levels, compared to control rats. 
Table 1. Effect of monosodium glutamate on food consumption in rats ( $g / d a y)$

\begin{tabular}{llll}
\hline Dose $(\mathbf{m g} / \mathbf{k g})$ & Week 1 & Week 2 & Week 3 \\
\hline Control & $73.06 \pm 8.43$ & $76.11 \pm 7.38$ & $79.51 \pm 12.20$ \\
5 & $65.47 \pm 5.33$ & $64.82 \pm 5.14$ & $67.52 \pm 8.28$ \\
10 & $61.61 \pm 6.05$ & $63.81 \pm 8.00$ & $68.52 \pm 8.23$ \\
15 & $68.91 \pm 6.27$ & $70.84 \pm 9.20$ & $72.21 \pm 7.49$ \\
\hline
\end{tabular}

Values represent mean $\pm \operatorname{SEM}(n=6)$

Table 2. Effect of monosodium glutamate on average body weight of rats ( $g$ )

\begin{tabular}{llllll}
\hline Dose $(\mathbf{m g} / \mathbf{k g})$ & Week 0 & Week 1 & Week 2 & Week 3 & Week 4 \\
\hline Control & $183.42 \pm 7.12$ & $185.82 \pm 10.25$ & $186.72 \pm 8.81$ & $188.22 \pm 10.72$ \\
5 & $185.27 \pm 7.52$ & $187.19 \pm 9.54$ & $189.42 \pm 10.38$ & $190.47 \pm 9.63$ \\
10 & $180.50 \pm 5.88$ & $182.94 \pm 8.67$ & $183.61 \pm 7.86$ & $185.20 \pm 10.59$ \\
15 & $182.03 \pm 10.73$ & $184.63 \pm 6.03$ & $186.22 \pm 8.86$ & 18.20 \\
\hline
\end{tabular}

Values represent mean $\pm \operatorname{SEM}(n=6)$

Table 3. Effect of monosodium glutamate on hematological parameters in rats

\begin{tabular}{|c|c|c|c|c|}
\hline \multirow[b]{2}{*}{ Parameter } & \multicolumn{4}{|c|}{ Treated groups } \\
\hline & Control & 5 & 10 & 15 \\
\hline $\mathrm{RBC}\left(\mathrm{x} 10^{12} / \mathrm{L}\right)$ & $9.19 \pm 0.24$ & $9.34 \pm 0.78$ & $9.63 \pm 0.61$ & $9.35 \pm 0.16$ \\
\hline PCV (\%) & $43.63 \pm 4.13$ & $43.34 \pm 2.40$ & $42.98 \pm 2.94$ & $43.52 \pm 5.14$ \\
\hline $\mathrm{HB}(\mathrm{g} / \mathrm{dL})$ & $18.64 \pm 1.53$ & $18.84 \pm 2.42$ & $19.15 \pm 2.66$ & $18.43 \pm 2.51$ \\
\hline WBC $\left(\times 10^{9} / \mathrm{L}\right)$ & $15.80 \pm 2.73$ & $15.69 \pm 2.84$ & $16.01 \pm 3.62$ & $15.22 \pm 215$ \\
\hline
\end{tabular}

Values represent mean $\pm \operatorname{SEM}(\mathrm{n}=6)$

Table 4. Effect of monosodium glutamate on biochemical parameters in rats

\begin{tabular}{|c|c|c|c|c|}
\hline \multicolumn{5}{|c|}{ Treated groups (mg/kg) } \\
\hline Parameters & Control & 5 & 10 & 15 \\
\hline AST (IU/L) & $148.51 \pm 6.02$ & $146.98 \pm 5.33$ & $148.95 \pm 8.44$ & $147.83 \pm 6.34$ \\
\hline ALT (IU/L) & $68.26 \pm 7.41$ & $69.15 \pm 5.82$ & $68.69 \pm 2.45$ & $68.43 \pm 5.63$ \\
\hline $\operatorname{ALP}(I U / L)$ & $144.65 \pm 5.65$ & $146.04 \pm 7.58$ & $145.08 \pm 6.72$ & $146.54 \pm 5.83$ \\
\hline Creatinine $(\mathrm{mg} / \mathrm{dL})$ & $0.71 \pm 0.05$ & $0.77 \pm 0.41$ & $0.69 \pm 0.17$ & $0.72 \pm 0.15$ \\
\hline Urea $(\mathrm{mg} / \mathrm{dL})$ & $29.55 \pm 5.64$ & $29.89 \pm 2.66$ & $30.24 \pm 3.22$ & $31.06 \pm 3.54$ \\
\hline Total protein (mg/dL) & $8.48 \pm 1.26$ & $8.25 \pm 0.64$ & $7.98 \pm 2.40$ & $8.16 \pm 1.27$ \\
\hline Albumin (mg/dL) & $5.53 \pm 1.44$ & $5.36 \pm 1.27$ & $5.82 \pm 1.55$ & $5.48 \pm 0.85$ \\
\hline Globulin (mg/dL) & $2.95 \pm 0.69$ & $2.89 \pm 1.02$ & $2.16 \pm 0.27$ & $2.68 \pm 0.24$ \\
\hline Total bilirubin $(\mathrm{mg} / \mathrm{dL})$ & $1.36 \pm 0.50$ & $1.41 \pm 0.38$ & $1.29 \pm 0.47$ & $1.68 \pm 0.13$ \\
\hline
\end{tabular}

Values represents mean $\pm \operatorname{SEM}(n=6)$

On the other hand, Hermanussen et al. [18] reported that the ingestion of MSG increased body weight gain and food consumption in rats, implying that MSG could cause obesity and metabolic disorders.

In all the three doses of MSG used in the present study, there was no significant change in food consumption pattern (Table 1) and change in body weight (Table2) of rats when the treated groups were compared with the control group. These results corroborate recent findings by Maluly et al. [19] who reported that ingestion of MSG had no effects on body weight gain as well as food consumption in rats. Tordoff et al. [20] also reported that MSG did not influence body weight, energy intake or body composition in adult rats and mice. The authors emphasized that MSG is unlikely to cause obesity or be employed as anti-obesity supplement.

Likewise there are reports suggesting that MSG could be toxic to erythrocytes and also cause deleterious changes in hematological and biochemical parameters [21, 22]. The present study demonstrated that MSG at the doses administered did not cause any significant change in packed cell volume (PCV), hemoglobin concentration (HB), red blood cell (RBC) and white blood cell (WBC) counts as shown in Table 3. No significant change was also observed in all the biochemical parameters studied, including indices of hepatic and kidney functions (Table 4). These results are again in agreement with the work of Maluly et al. [19] who reported similar findings.

It should be noted that in most of the studies that have reported that MSG is unsafe for use, MSG was administered to immature rodents. The results of such studies may not be readily transferable to adult humans. Also, in human, intake of glutamate by suckling babies through the mother's milk is seen as beneficial for physiological support of growth due to its central role in transamination processes [23, 24].

Under normal circumstances, the acute toxicity of glutamate is very low. The oral median lethal dose $\left(\mathrm{LD}_{50}\right)$ for mice and rats are 1.5 and $1.8 \mathrm{~g} / \mathrm{kg}$ respectively [24, 25]. 
Likewise no specific adverse effects were observed at dietary level of up to $4 \%$ in sub-chronic and chronic toxicity studies that lasted 2 years $[24,25]$.

Several government institutions and international organizations have declared that MSG is safe for human consumption. The U.S. Food and Drug Administration (FDA) designated glutamate as a GRAS (Generally Recognized AS Safe) ingredient [4]. Other organizations which have asserted that glutamate is safe as food additive include the Joint Expert Committee on Food Additives of the United Nations Food and Agriculture Organization and World Health Organization [10] and the Scientific Committee for Food of the European Union [26]. JECFA concluded that the total dietary intake of glutamate at the level necessary to achieve desired effect on foods is not hazardous to health. Therefore the organization allocated an "ADI not specified" to MSG which indicates that there is no need for the establishment of an acceptable daily intake (ADI) and there is no reason for toxicity concern when it is used in accordance with good manufacturing practices (GMPs).

\section{Conclusion}

In the present study, MSG did not cause any observable changes in rats. It is therefore concluded that the use of MSG as food additive is not unsafe.

\section{References}

[1] Chi, S. P. and Chen, T.C. Predicting optimum monosodium glutamate and sodium chloride concentrations in chicken broth as affected by spice addition. Journal of Food Processing and Preservation, 16: 313-326. (1992)

[2] Bellisle, F. Experimental studies of food choices and palatability responses in European subjects exposed to the umami taste. Asia Pacific Journal of Clinical Nutrition, 17(S1): 376-379. (2008)

[3] Yoshida, Y. Umami taste and traditional seasoning. Food Review International, 14(2): 213-246. (1998)

[4] Jinap, S. and Hajeb P. Glutamate: Its applications in food and contribution to health. Appetite, 55: 1-10. (2010)

[5] Farombi, E. O. and Onyema, O.O. Monosodium glutamate-induced oxidative damage and genotoxicity in the rat: modulatory role of vitamin $\mathrm{C}$, vitamin $\mathrm{E}$ and guercetin. Human Experimental Toxicol. 125: 251-259. (2006)

[6] Freeman, M. Reconsidering the effects of monosodium glutamate. A literature review. Journal of American Academy of Nurse Practitioners, 18(10): 482-486. (2006)

[7] He, K., L.,Zhao, Daviglus, M.L., Dyer, A.R., Horn, L.V., Garside, D., Zhu, L., Guo, D., Wu, Y., Zhou, B., Stamler, J. Association of monosodium glutamate intake with overweight in Chinese adults: the INTERMAP Study. Obesity, 16(8): 1875-1880. (2008)
[8] Cortese, B.M. and Phan, L.K. The Role of Glutamate in Anxiety and Related Disorders. CNS Spectr., 10(10): 820-830. (2005)

[9] International Food Information Council Foundation (IFIC), Washington, DC 20036. Available from: http://ific.org (2003)

[10] Joint FAO/WHO Expert Committee on Food Additives (JECFA), L-glutamic acid and its ammonium, calcium, monosodium and potassium salts. Toxicological Evaluation of Certain Food Additives and Contaminants 1988:97-161. New York Cambridge University Press. (1988)

[11] Kondoh, T. and Torii, K. MSG intake suppresses weight gain, fat deposition and plasma leptin levels in male Sprague-Dawley rats. Physiology and Behavior, 95: 135-144. (2008)

[12] Ebert, A. G. Response to "Evidence that MSG does not induce obesity". Obesity, 17(4): 629-630. (2010)

[13] National Institute of Health (NIH). Guide for the use of laboratory animals. DHHS, PHS, NIH Publication No. 85-23 (1985 Revised). (1985)

[14] Dacie, J.V. and Lewis, S.M. Practical Hematology. 6th Edn., Churchill Livingston, Edinburgh, Melbourne and New York. Pp. 24-36. (1984)

[15] Ramnik, S. Medical Laboratory Technology: Methods and Interpretations. 5th Edn., Jayee Brothers, New Delhi, pp. 279. (1999)

[16] Toro, G. and Ackermann, P.G. The Practical Clinical Chemistry. 1st Edn., Little Brown and Co. Inc., Boston, USA. (1975)

[17] Schiffman, S.S. Intensification of sensory properties of foods for the elderly. Journal of Nutrition, 130: 927S-930S. (2000)

[18] Hermanussen, M., Garcia, A.P., Sunder, M., Voigt, M., Salazar, V., Tresguerres, J.A.F. "Obesity, Voracity, and Short Stature: the impact of glutamate on the regulation of appetite". European Journal of Clinical Nutrition. 60: 25-31. (2006)

[19] Maluly, H.D.B., Areas, M.A., Borelli, P., Reyes, F.G.R. Evaluation of biochemical, hematological and histological parameters in non diabetic and diabetic wistar rats fed monosodium glutamate. Food and Nutrition sciences, 4: 66-76. (2013)

[20] Tordoff, M.G., Aleman, T.R., Murphy, M.C. No effects of monosodium glutamate consumption on the body weight or composition of adult rats and mice. Physiol Behav. 107: 338-345. (2012)

[21] Ashaolu, J.O., Ukwenya, V.O., Okonoboh, A.B., Ghazal, O.K., Jimoh, A.A.G. Effect of monosodium glutamate on hematological parameters in Wistar rats. International journal of Medicine and Medical Sciences, 3(6): 219-222. (2011)

[22] Meraiyebu, A., Akintayo, C.O., Uzoechi, A.C., Okere, S. The effects of orally administered monosodium glutamate (MSG) on blood thrombocyte, blood coagulation and bleeding in rats. IOSR Journal of Pharmacy and Biological Sciences, 4(1): 4-8. (2012) 
[23] Jochum, F., Meinardus, P., Alteheld, B. Colling, S., Fusch, C., Stehle, P. Total glutamine content in preterm and term human breast milk, 95: 985-990. (2006)

[24] Beyreuther, K., Biesalski, H.K., Fernstrom, J.D., Grimm, P., Hammes, W.P., Heinemann, U., Kempski, O., Stehle, P., Steinhart, H., Walker, R. Consensus meeting: monosodium glutamate - an update. European Journal of Clinical Nutrition, 60: 1-10. (2006)
[25] Walker, R. and Lupien, J.R. The safety evaluation of monosodium glutamate. Journal of Nutrition, 130: 1049S1052S. (2000)

[26] Scientific Committee for Food (SCF). Reports of the Scientific Committee for Food on a First Series of Food Additives of Various Technological Functions, Commission of the European Communities, Reports of the Scientific Committee for Food, 25th Series. Brussels, Belgium. (1991). 